\title{
Nonlinear Oscillations of a Pendulum Wrapped Around a Cylinder
}

\author{
Anastas Ivanov Ivanov ${ }^{1^{*}}$ \\ ${ }^{1}$ Department Mechanics, Todor Kableshkov University of Transport, Sofia (Bulgaria)
}

The large oscillations of a pendulum are studied. The pendulum is a material point that is suspended on an elastic cord with nonlinear characteristics. The mass of the cord is accepted. It is wrapped around a perfectly rigid and fixed cylinder. The system has two degrees of freedom. Nonlinearity is due to a geometric and physical nature. A system of two differential nonlinear equations is derived. A numerical solution was performed with the mathematical package MATLAB. The laws of motion, the generalized velocities and accelerations and the phase trajectories are obtained. In order to continue the task by preparing an actual model and conducting experimental research, the projections of the velocity and acceleration of the material point along the horizontal and vertical axes, as well as their magnitudes, are determined. The obtained results are presented graphically and analysed in detail.

Keywords: Pendulum, Geometric and physical nonlinearity, Nonlinear oscilations

\section{INTRODUCTION}

The pendulum has been the subject of researches from ancient times. During the Renaissance, the phenomenal periodic movements of the pendulum were studied by Leonardo da Vinci and Galileo Galilei, [1].

In 1656, the Dutch scientist Christiaan Huygens constructed a pendulum clock. Such clocks remained the most accurate instruments for measuring time until the 1930 year, [2].

In 1851, Jean-Bernard Leon Foucault constructed a mathematical pendulum to prove the rotation of the Earth around the North-South axis, [3].

Analytical solutions related to the study of small and large oscillations of the pendulum provide a field for the development of a number of branches of Mathematics. To this day, many scientists, when studying the large nonlinear oscillations of the pendulum, apply analytical solutions, [4].

In the work [5], a few terms of the Fourier series expansion of the elliptic function as a source of periodic solutions for the pendulum equation are studied.

The nonlinear oscillation of a pendulum wrapping and unwrapping on two cylindrical bases is studied in the article [6]. An analytical solution is obtained using the multiple scales method.

The nonlinear oscillations of a pendulum wrapping on two cylinders is studies by means of a new analytical technique, namely the optimal auxiliary function method are studied in the publication [7].

A detailed theoretical and computational analysis of the period, tension and centripetal forces are studied in the paper [8].

The dynamical behavior of rigid weightless rod and concentrated mass, sliding periodically along the axis of the rod is studied in the article [9].

The dynamical behavior of rigid weightless rod and concentrated mass, moving simultaneously along and across the axis of the rod, according to given periodical laws is studied in article [10].

Today, in the presence of powerful electronic computing equipment and modern mathematical packages, such as MATLAB, Mathcad, Mathematica, and others, these solutions are made mainly numerically, $[11,12,13$, 14]. They are particularly suitable for optimizing some parameters, [15].

The present study complicates the classical dynamic model of the mathematical pendulum in two directions simultaneously.

The cord is wrapped around a stationary cylinder. This leads to the lack of a fixed center of rotation and determines a variable length of the cord at any moment of time. Therefore, there is a specific geometric nonlinearity.

The cord is considered to be elastic with a soft characteristic, unlike the classic models, where the cord is inextensible. This leads to the typical physical nonlinearity.

The main goals of this study are the following:

1. To obtain the differential equations that describe the big oscillations of the mathematical pendulum taking into account both the geometric and physical nonlinearity of the model.

2. To compile a program for numerical integration of the derived nonlinear differential equations in the area of the mathematical package MatLab, and after then, to perform a computer simulation.

3. The study should be a basis for continuing the task by preparing a real pendulum and conducting of experimental researches, $[16,17,18,19,20]$.

\section{MATHEMATICAL MODEL}

The mathematical pendulum studied in this work is a material point $M$ with concentrated mass $m$, which is connected by an elastic cord with distributed mass $\bar{m}$. The cord is wrapped around a fixed rigid cylinder with a radius $R$. In a stable equilibrium position and at rest, when the 
cord is vertical, its length is $L$. This is the distance between the points $A$ and $M_{0}$, (Figure 1).

If the cord is perfectly un-deformable, when the pendulum deviates at an angle $\varphi$, it increases its length, according to the formula:

$$
P M=L+R \cdot \varphi \text {. }
$$

In the studied case, the cord is elastic, and when the pendulum deviates at an angle $\varphi$, it increases its length with the additional linear deformation $u$ and acquires the following length:

$$
P M=L+R \cdot \varphi+u \text {. }
$$

The point $P$, where the cord separates from the cylinder, represents the center of rotation or center of velocities at any moment of time.

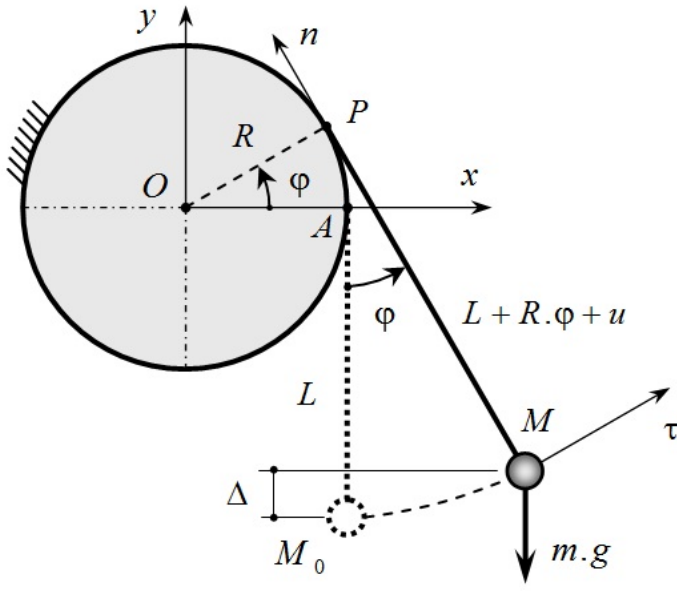

Figure 1: Mathematical pendulum with elastic cord wrapped around a fixed cylinder

It is assumed that the pendulum moves in a vertical plane under the action of the potential force of gravity $m . g$. This plane coincides with the plane of the fixed coordinate system $O x y$ and the mobile coordinate system $M \tau n$.

The system has two degrees of freedom. For independent generalized coordinates that define the position of a point $M$, the angle $\varphi$ and extension $u$ of the cord are assumed. The first coordinate is absolute and the second one is relative.

\section{DIFFERENTIAL EQUATIONS}

The mechanical system is conservative. Its study is carried out with the Lagrange equations of the second kind:

$$
\begin{aligned}
& \frac{d}{d t}\left(\frac{\partial E_{k}}{\partial \dot{\varphi}}\right)-\frac{\partial E_{k}}{\partial \varphi}=-\frac{\partial E_{p}}{\partial \varphi}, \\
& \frac{d}{d t}\left(\frac{\partial E_{k}}{\partial \dot{u}}\right)-\frac{\partial E_{k}}{\partial u}=-\frac{\partial E_{p}}{\partial u} .
\end{aligned}
$$

The first equation (3) is composed by the absolute coordinate $\varphi$, and the second equation (4) - by the relative coordinate $u$.

The kinetic energy of the pendulum is as follows:

$$
\begin{aligned}
E_{k}= & \frac{1}{2} \cdot m \cdot(L+R \cdot \varphi+u)^{2} \cdot \dot{\varphi}^{2}+\frac{1}{2} \cdot m \cdot \dot{u}^{2} \\
& +\frac{1}{6} \cdot \bar{m} \cdot(L+R \cdot \varphi+u)^{3} \cdot \dot{\varphi}^{2} \\
& +\frac{1}{6} \cdot \bar{m} \cdot(L+R \cdot \varphi+u) \cdot \dot{u}^{2} .
\end{aligned}
$$

The connection between the internal elastic force $F_{e l}$ in the cord, due to its elongation $u$, is defined as follows:

$$
F_{e l}=c \cdot u-c_{1} \cdot u^{3} .
$$

The potential energy of deformation is determined by the integral:

$$
U=\int_{0}^{u}\left(c \cdot x-c_{1} \cdot x^{3}\right) d x=\frac{1}{2} \cdot c \cdot u^{2}-\frac{1}{4} \cdot c_{1} \cdot u^{4} .
$$
by formula:

The full potential energy is obtained approximately

$$
\begin{gathered}
E_{p} \approx C_{0}+U+m \cdot g \cdot(L+R \cdot \sin \varphi) \\
\quad-m \cdot g \cdot(L+R \cdot \varphi+u) \cdot \cos \varphi \\
+\frac{1}{2} \cdot \bar{m} \cdot g \cdot L^{2}+\bar{m} \cdot g \cdot L \cdot R \cdot \sin \varphi \\
-\frac{1}{2} \cdot \bar{m} \cdot g \cdot(L+R \cdot \varphi+u)^{2} \cdot \cos \varphi,
\end{gathered}
$$

where $C_{0}=$ const is the potential energy of the system in a stable equilibrium position.

The following constant is constructed:

$$
\mu=\bar{m} / m \text {. }
$$

Formulas (5) and (8) are put in equations (3) and (4), and the following differential equations are reached:

$$
\begin{gathered}
(L+R \cdot \varphi+u) \cdot \ddot{\varphi}+\frac{\mu}{3} \cdot(L+R \cdot \varphi+u)^{2} \cdot \ddot{\varphi} \\
+R \cdot \dot{\varphi}^{2}+2 \cdot \dot{\varphi} \cdot \dot{u}+\frac{\mu}{2} \cdot R \cdot(L+R \cdot \varphi+u) \cdot \dot{\varphi}^{2} \\
+\mu \cdot(L+R \cdot \varphi+u) \cdot \dot{\varphi} \cdot \dot{u}-\frac{\mu}{6} \cdot R \cdot \frac{\dot{u}^{2}}{L+R \cdot \varphi+u} \\
+g \cdot \sin \varphi+\mu \cdot g \cdot L \cdot R \cdot \frac{\cos \varphi}{L+R \cdot \varphi+u}-\mu \cdot g \cdot R \cdot \cos \varphi \\
\quad+\frac{\mu}{2} \cdot g \cdot(L+R \cdot \varphi+u) \cdot \sin \varphi=0, \\
\ddot{u}+\frac{\mu}{3} \cdot(L+R \cdot \varphi+u) \cdot \ddot{u}++\frac{c}{m} \cdot u-\frac{c_{1}}{m} \cdot u^{3} \\
+\frac{\mu}{3} \cdot\left(R \cdot \dot{\varphi} \cdot \dot{u}+\dot{u}^{2}\right)-(L+R \cdot \varphi+u) \cdot \dot{\varphi}^{2} \\
-\frac{\mu}{2} \cdot(L+R \cdot \varphi+u)^{2} \cdot \dot{\varphi}^{2}-\frac{\mu}{6} \cdot \dot{u}^{2}-g \cdot \cos \varphi \\
\quad-\mu \cdot g \cdot(L+R \cdot \varphi+u) \cdot \cos \varphi=0 \cdot
\end{gathered}
$$

A homogeneous nonlinear system of two ordinary second-order differential equations is obtained. Its solution under appropriate initial conditions is performed numerically with a specially prepared program in the area of the mathematical package MATLAB.

For future experimental measurements of the velocity and the acceleration of point $M$, some formulas for the algebraic projections of absolute velocity and 
absolute acceleration relative to the axes of the fixed coordinate system $O x y$ are needed.

$$
\begin{aligned}
& \text { These expressions are the following: } \\
& \begin{aligned}
v_{x}= & (L+R \cdot \varphi+u) \cdot \dot{\varphi} \cdot \cos \varphi+\dot{u} \cdot \sin \varphi, \\
v_{y}= & (L+R \cdot \varphi+u) \cdot \dot{\varphi} \cdot \sin \varphi-\dot{u} \cdot \cos \varphi, \\
& a_{x}=(L+R \cdot \varphi+u) \cdot \ddot{\varphi} \cdot \cos \varphi \\
- & \left((L+R \cdot \varphi+u) \cdot \dot{\varphi}^{2}-\ddot{u}\right) \cdot \sin \varphi, \\
& a_{y}=(L+R \cdot \varphi+u) \cdot \ddot{\varphi} \cdot \sin \varphi \\
+ & \left((L+R \cdot \varphi+u) \cdot \dot{\varphi}^{2}-\ddot{u}\right) \cdot \cos \varphi .
\end{aligned}
\end{aligned}
$$

The magnitudes of the velocity and acceleration of point $M$ are as follows:

$$
\begin{gathered}
v=\sqrt{(L+R \cdot \varphi+u)^{2} \cdot \dot{\varphi}^{2}+\dot{u}^{2}}, \\
a=\left((L+R \cdot \varphi+u)^{2} \cdot \ddot{\varphi}^{2}\right. \\
\left.+\left((L+R \cdot \varphi+u) \cdot \dot{\varphi}^{2}-\ddot{u}\right)^{2}\right)^{0.5} .
\end{gathered}
$$

It can be seen from the derived formulas that the main purpose of the study is to determine both laws $\varphi=\varphi(t)$ and $u=u(t)$.

The elastic cord is a one-way connection. This means that it can function only if it is tensioned at any time during the movement of the pendulum. The condition for the cord to be tensioned is as follows:

$$
S=m \cdot\left(g \cdot \cos \varphi-\ddot{u}+(L+R \cdot \varphi+u) \cdot \dot{\varphi}^{2}\right)>0 .
$$

Therefore, the initial conditions must be set inappropriate values that they take into account the elastic characteristics of the cord.

\section{NUMERICAL SULUTIONS}

The numerical integration of the system of differential equations (10) and (11) is performed with the solver ode45 of MATLAB, based on the explicit RungeKuta method of 4 th and 5 th order. This is a one-step algorithm with a chosen fixed-step $\Delta t=0.001 \mathrm{~s}$. This method calculates the value of function $f\left(t_{n}\right)$ using only one previous value of function $f\left(t_{n-1}\right)$.

The solver ode45 is the most used in such studies and guarantees relative accuracy $\varepsilon_{r}=1.10^{-6}$ and absolute accuracy $\varepsilon_{a}=1.10^{-8}$.

The parameters with which the calculations were performed are: $m=1.50 \mathrm{~kg}, \quad R=0.50 \mathrm{~m}, L=2 \mathrm{~m}$, $c=250 \mathrm{~N} / \mathrm{m}$, and $c_{1}=20 \mathrm{~N} / \mathrm{m}^{3}, \bar{m}=0.10 \mathrm{~kg} / \mathrm{m}$.

The following initial conditions are accepted:

$\varphi_{0}=\pi / 4 \mathrm{rad}, \quad \dot{\varphi}_{0}=0 \mathrm{~s}^{-1}, \quad u_{0}=0.05 \mathrm{~m} \quad$ and $\dot{u}_{0}=0 \mathrm{~m} / \mathrm{s}$.

In order to ignore the transient processes, a longer integration time was adopted, namely $t=10 \mathrm{~s}$. obtained

The following kinematic characteristics were

a.) Laws of the first generalized coordinate, $\varphi(t)$, $\dot{\varphi}(t), \ddot{\varphi}(t)$, (Figures 2, 3 and 4);

b.) Laws of the second generalized coordinate, $u(t), \dot{u}(t), \ddot{u}(t),($ Figures 5, 6 and 7); c.) Velocity of point $M, v_{x}(t), v_{y}(t), v(t)$, (Figures 8, 9 and 10);

d.) Acceleration of point $M, a_{x}(t), a_{y}(t), a(t)$, (Figures 11, 12 and 13);

e.) Phase trajectories of point, $M, \dot{\varphi}=\dot{\varphi}(\varphi)$ and $\dot{u}=\dot{u}(u)$, (Figures 14 and 15);

f.) Tensile force in the cord, $S=S(t)$, (Figure 16).

The law $\varphi(t)$ is a periodic function with period $T=3.025 \mathrm{~s}$, natural frequency $f=0.331 \mathrm{~Hz}$, and

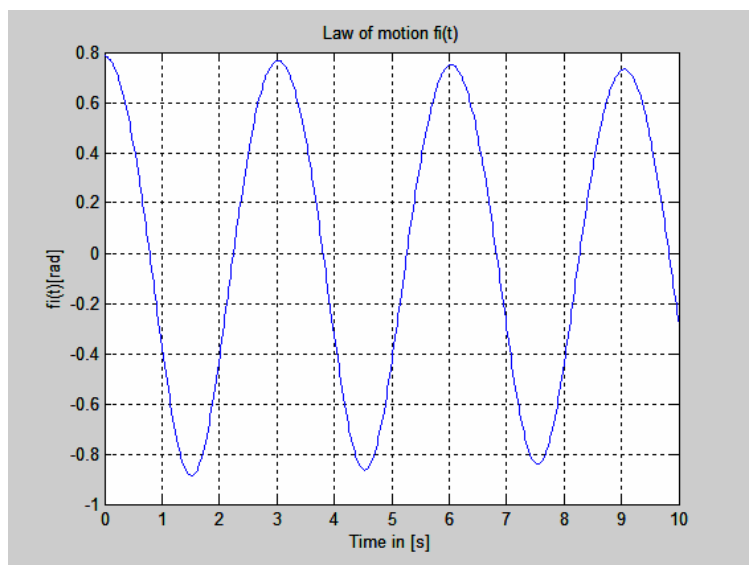

Figure 2: Law of angle function, $\varphi=\varphi(t) \mathrm{rad}$

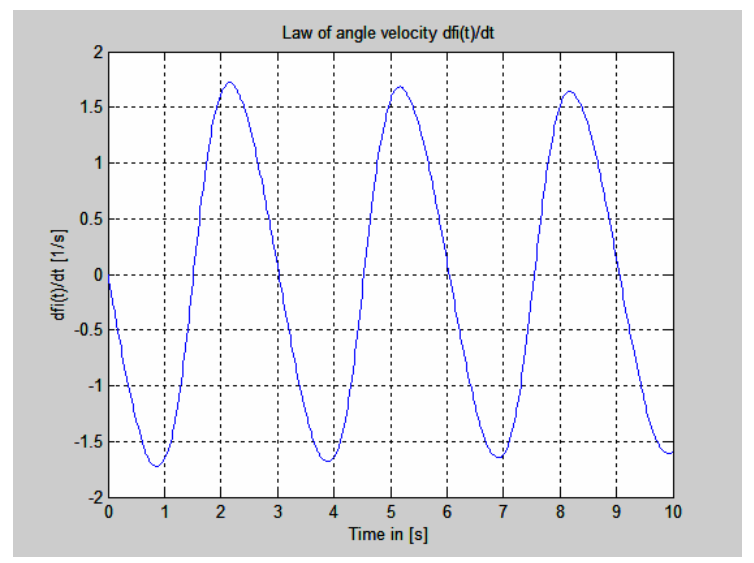

Figure 3: Law of angle velociy, $\dot{\varphi}=\dot{\varphi}(t) s^{-1}$

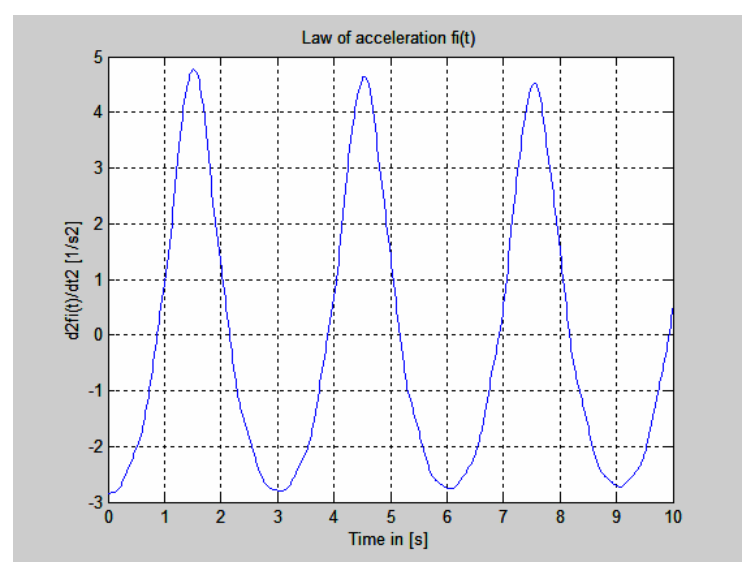

Figure 4: Law of angle acceleration, $\ddot{\varphi}=\ddot{\varphi}(t) s^{-2}$ circular frequency $\omega=2.077 \mathrm{~s}^{-1}$ 
The maximum angular velocity is $\max |\dot{\varphi}|=1.7227 s^{-1}$. The extreme values of the angular acceleration are $\max |\ddot{\varphi}|=4.8207 s^{-2}$ and $\min |\ddot{\varphi}|=2.8569 s^{-2}$.

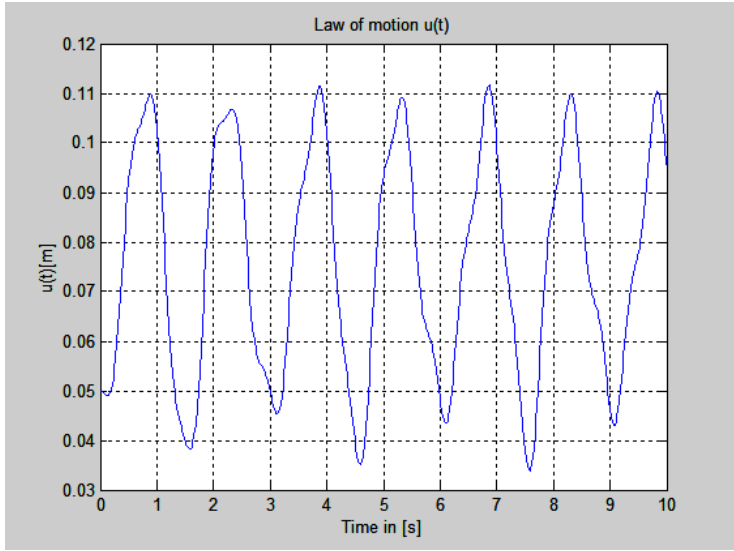

Figure 5: Law of motion $u=u(t) m$

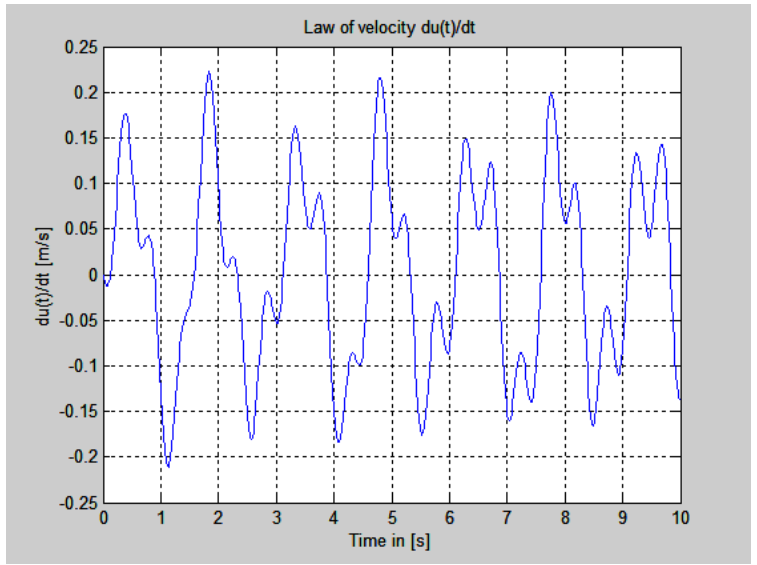

Figure 6: Law of velocity $\dot{u}=\dot{u}(t) \mathrm{m} / \mathrm{s}$

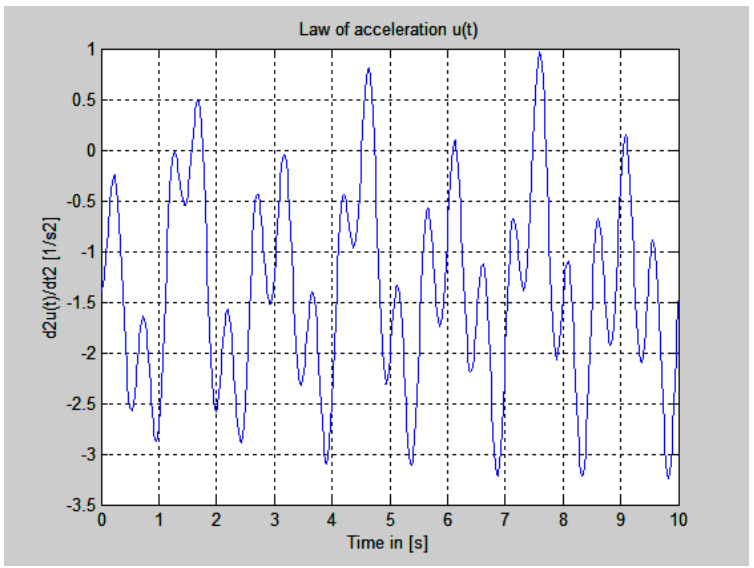

Figure 7: Law of acceleration

$$
\ddot{u}=\ddot{u}(t) \mathrm{m} / \mathrm{s}^{2}
$$

The laws $u(t), \dot{u}(t)$ and $\ddot{u}(t)$ are periodic indeterminate functions of time. The extreme values are $0.0340 m \leq u(t) \leq 0.1115 \mathrm{~m}, \max |\dot{u}|=0.2231 \mathrm{~m} / \mathrm{s}$ and $\max |\ddot{u}|=1.6205 \mathrm{~m} / \mathrm{s}^{2}$.

The laws of velocity $v_{x}(t), v_{y}(t)$ and $v(t)$ are periodic functions with maximum values $\max \left|v_{x}\right|=3.5610 \mathrm{~m} / \mathrm{s}, \max \left|v_{y}\right|=1.6010 \mathrm{~m} / \mathrm{s}$ and
$0.0320 \mathrm{~m} / \mathrm{s} \leq v(t) \leq 3.6020 \mathrm{~m} / \mathrm{s}$.

The laws of acceleration $a_{x}(t), a_{y}(t)$ and $a(t)$ are periodic functions with values, namely $-6.9034 \mathrm{~m} / \mathrm{s}^{2} \leq a_{x} \leq 6.0740 \mathrm{~m} / \mathrm{s}^{2}$,

$-5.4295 \mathrm{~m} / \mathrm{s}^{2} \leq a_{y} \leq 3.5482 \mathrm{~m} / \mathrm{s}^{2}$,

$4.7046 \mathrm{~m} / \mathrm{s}^{2} \leq a \leq 7.6962 \mathrm{~m} / \mathrm{s}^{2}$.

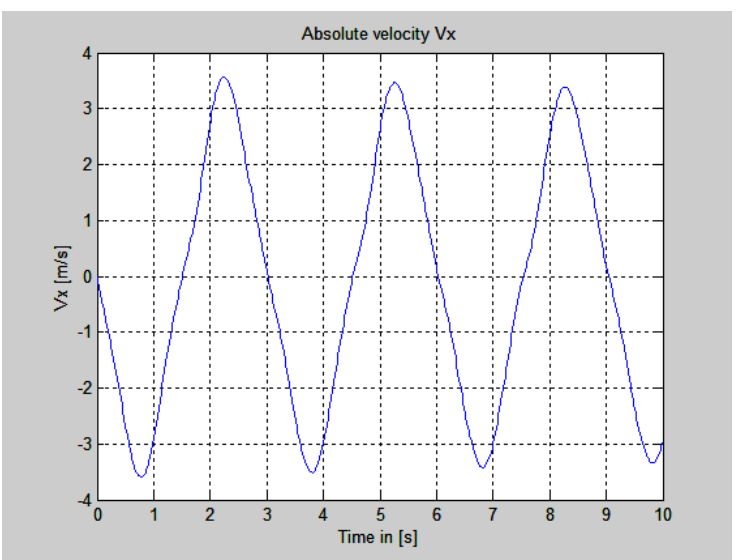

Figure 8: Velocity $v_{x}$ of point $M$ : $v_{x}=v_{x}(t) m / s$

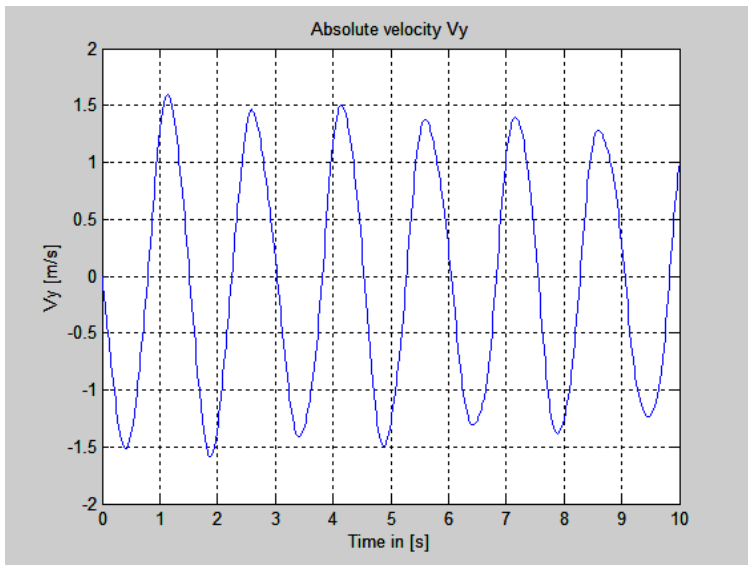

Figure 9: Velocity $v_{y}$ of point $M$ : $v_{y}=v_{y}(t) \mathrm{m} / \mathrm{s}$

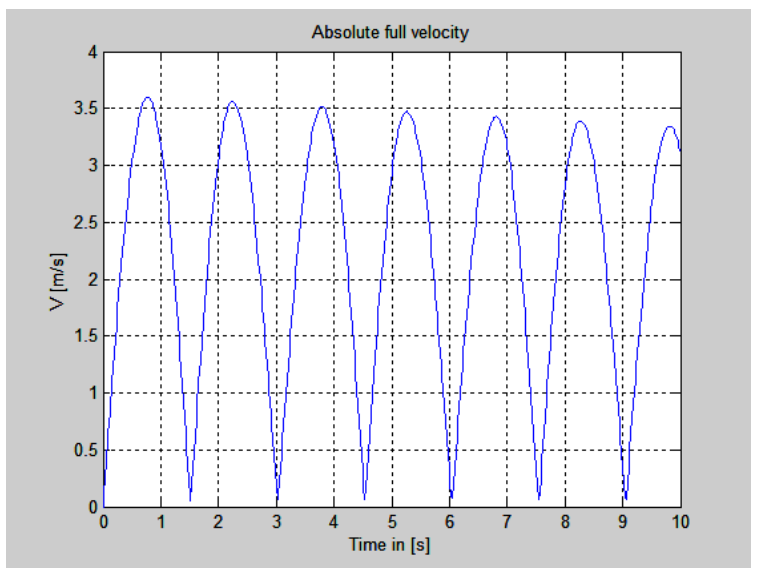

Figure 9: Velocity $v$ of point $M$ :

$$
v=v(t) \mathrm{m} / \mathrm{s}
$$

The inner force $S(t)$ in the cord has always a positive value, or in other words, the cord is always loaded with tensile force. This force is in the range 


\section{$7.4519 N \leq S(t) \leq 16.8625 N$}

The phase trajectories of Figure 14 and Figure 15 fully correspond to the obtained laws $\varphi(t), \dot{\varphi}(t), u(t)$ and $\dot{u}(t)$.

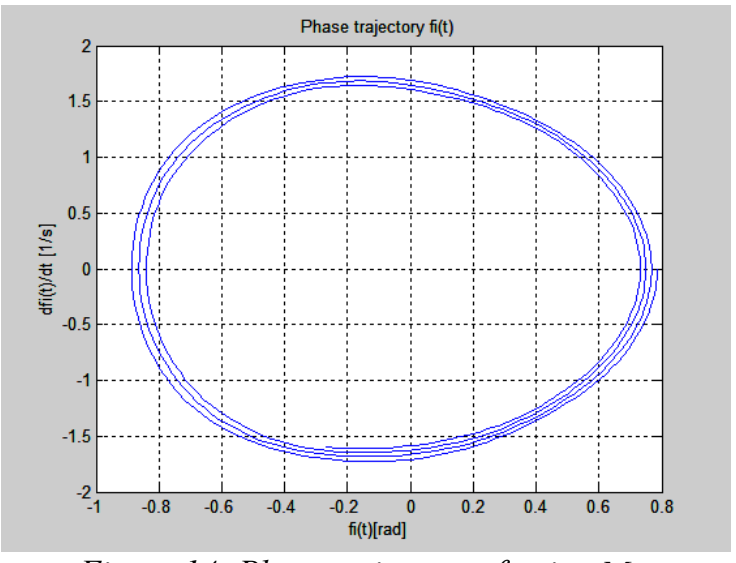

Figure 14: Phase trajectory of point $M$ : $\dot{\varphi}=\dot{\varphi}(\varphi)$

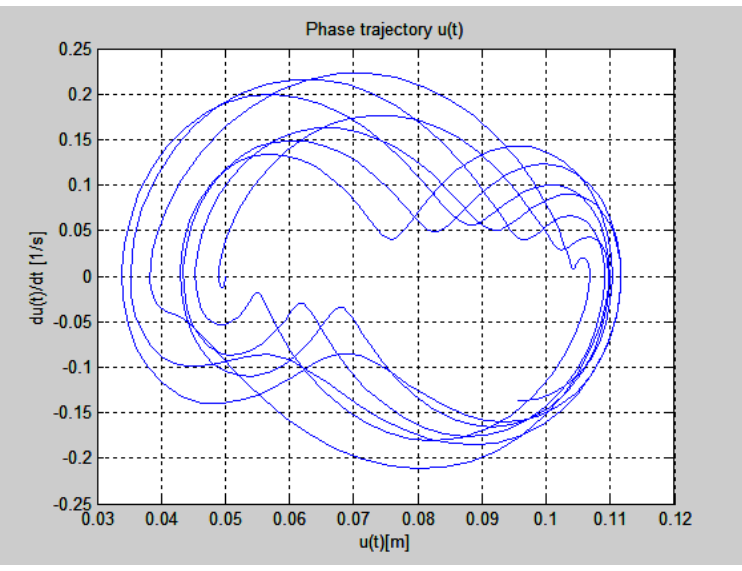

Figure 15: Phase trajectory of point $M$ : $\dot{u}=\dot{u}(u)$

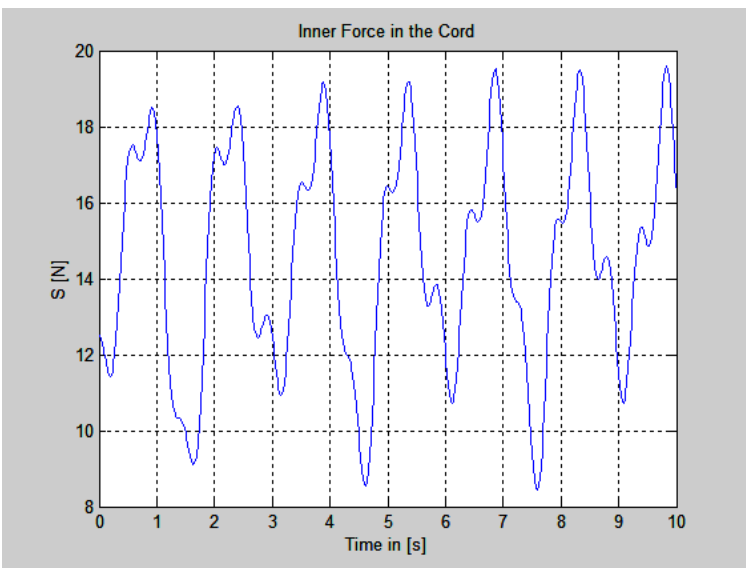

Figure 16: Tensile force in the cord:

$$
S=S(t) N
$$

If an analysis of the phase trajectory $\dot{\varphi}=\dot{\varphi}(\varphi)$ of Figure 14 is made, it will be seen that the distributed mass $\bar{m}$ causes a gradual attenuation of the oscillations. To demonstrate this, two calculations are made.
Figure 17 shows the phase trajectory $\dot{\varphi}=\dot{\varphi}(\varphi)$ at $\bar{m}=0 \mathrm{~kg} / \mathrm{m}$ and $c_{1}=0 \mathrm{~N} / \mathrm{m}^{3}$. Moreover, the integration time is increased to $t=25 \mathrm{~s}$.

Figure 18 shows the phase trajectory $\dot{\varphi}=\dot{\varphi}(\varphi)$ at $\bar{m}=0.50 \mathrm{~kg} / \mathrm{m}, c_{1}=0 \mathrm{~N} / \mathrm{m}^{3}$ and integration time is $t=25 \mathrm{~s}$.

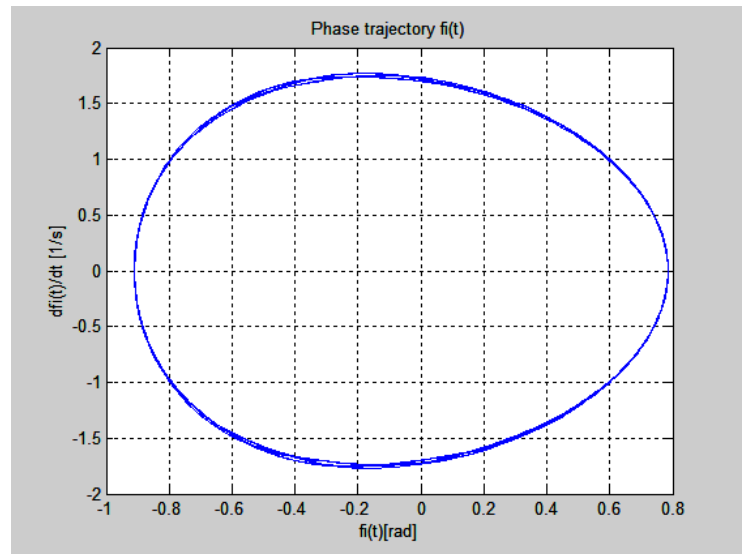

Figure 17: Phase trajectory of point $M$ : $\dot{\varphi}=\dot{\varphi}(\varphi), \bar{m}=0 \mathrm{~kg} / \mathrm{m}, c_{1}=0 \mathrm{~N} / \mathrm{m}^{3}$

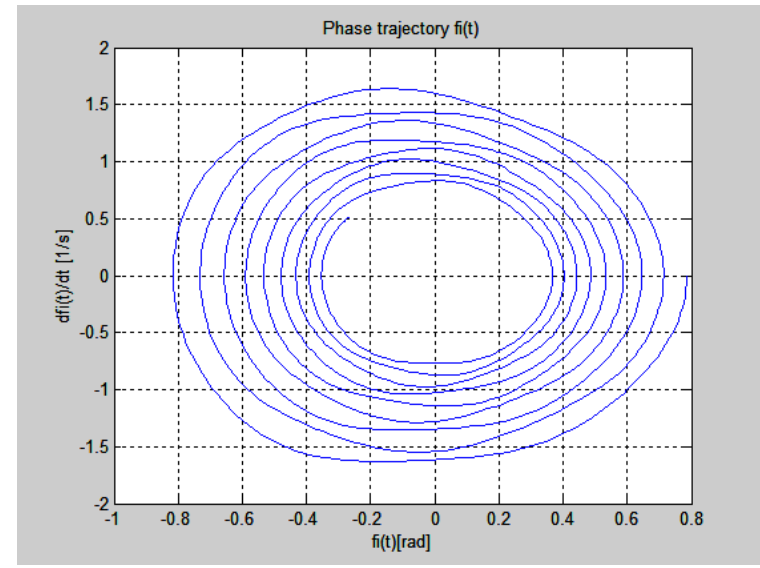

Figure 18: Phase trajectory of point $M$ : $\dot{\varphi}=\dot{\varphi}(\varphi), \bar{m}=0.50 \mathrm{~kg} / \mathrm{m}, c_{1}=0 \mathrm{~N} / \mathrm{m}^{3}$

The analysis of the phase trajectory $\dot{u}=\dot{u}(u)$ for two states is made.

At the first state, it is accepted $\bar{m}=0 \mathrm{~kg} / \mathrm{m}$ and $c_{1}=0 \mathrm{~N} / \mathrm{m}^{3}$. The integration time is increased to $t=60 \mathrm{~s}$. The obtained phase trajectory is shown in Figure 19.

At the second state, it is accepted $\bar{m}=0.50 \mathrm{~kg} / \mathrm{m}$, and $c_{1}=0 \mathrm{~N} / \mathrm{m}^{3}$. The integration is also $t=60 \mathrm{~s}$. The obtained phase trajectory is shown in Figure 20.

The analysis shows that if the distributed mass $\bar{m}$ of the cord is increased, the longitudinal oscillations $u(t)$ also decrease. They are moved to another zone and are established in some constant limits.

The case for the influence of the stiffness of the cord is also interesting. To establish this effect, two calculations for $\bar{m}=0.10 \mathrm{~kg} / \mathrm{m}, \quad c_{1}=50 \mathrm{~N} / \mathrm{m}^{3}$ and integration time $t=60 \mathrm{~s}$ were performed. 
The first calculation is made with the coefficient of elasticity $c=300 \mathrm{~N} / \mathrm{m}$, and the second calculation is made with the coefficient of elasticity $c=900 \mathrm{~N} / \mathrm{m} \mathrm{s}$.

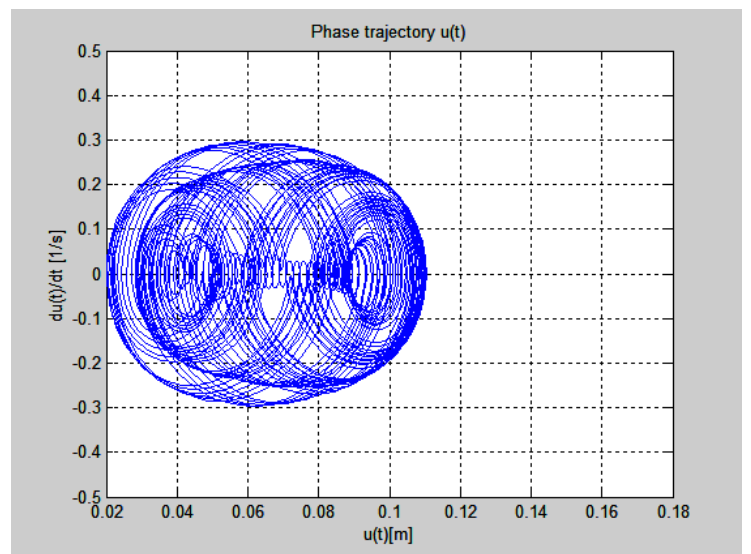

Figure 19: Phase trajectory of point $M$ : $\dot{u}=\dot{u}(u), \bar{m}=0 \mathrm{~kg} / \mathrm{m}, c_{1}=0 \mathrm{~N} / \mathrm{m}^{3}$

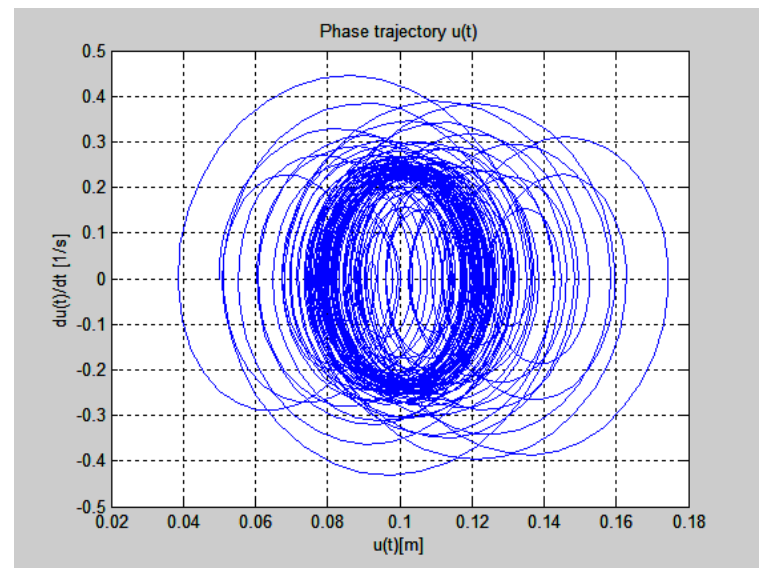

Figure 20: Phase trajectory of point $M$ : $\dot{u}=\dot{u}(u), \bar{m}=0.50 \mathrm{~kg} / \mathrm{m}, c_{1}=0 \mathrm{~N} / \mathrm{m}^{3}$

From the phase trajectories, shown in Figures 21 and 22 , it can be seen that as the coefficient of elasticity of the cord increases, the amplitudes of the longitudinal oscillations decrease, but the velocity increases. The phenomenon "beating" is observed on both phase trajectories, which is more pronounced in Figure 21 in comparison with Figure 22.

\section{CONCLUSION}

A mathematical model of a pendulum is created. It consists of a concentrated mass and an elastic mass cord, which is wrapped around a fixed cylinder.

Nonlinear differential equations are derived, which describe the oscillations of the pendulum and the oscillations of the material point in the longitudinal direction of the cord.

A program was compiled in the area of the MATLAB mathematical package, with the help of which all kinematical characteristics were obtained, namely: laws of motion, velocities and accelerations for the two generalized coordinates, linear velocities and accelerations of the concentrated mass, as well as the inner force of the elastic cord.
The phase trajectories $\dot{u}=\dot{u}(u)$ for the two states are shown in Figures 21 and 22.

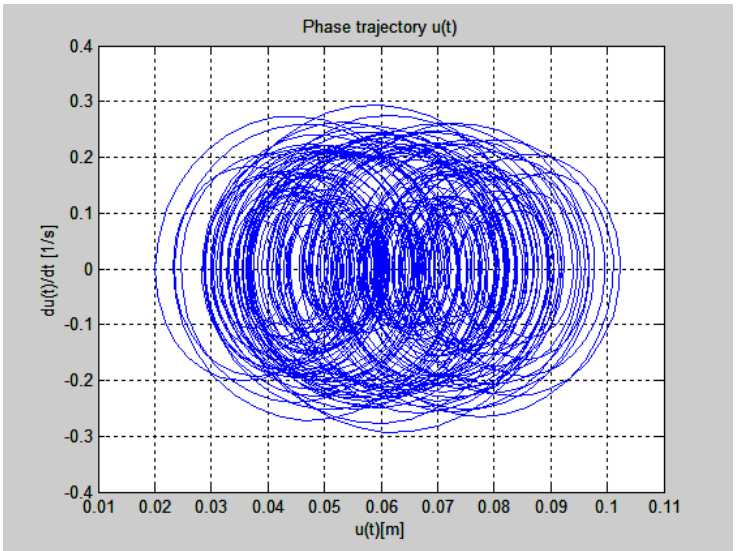

Figure 21: Phase trajectory of point $M$ : $\dot{u}=\dot{u}(u), \bar{m}=0.10 \mathrm{~kg} / \mathrm{m}, c=300 \mathrm{~N} / \mathrm{m}$

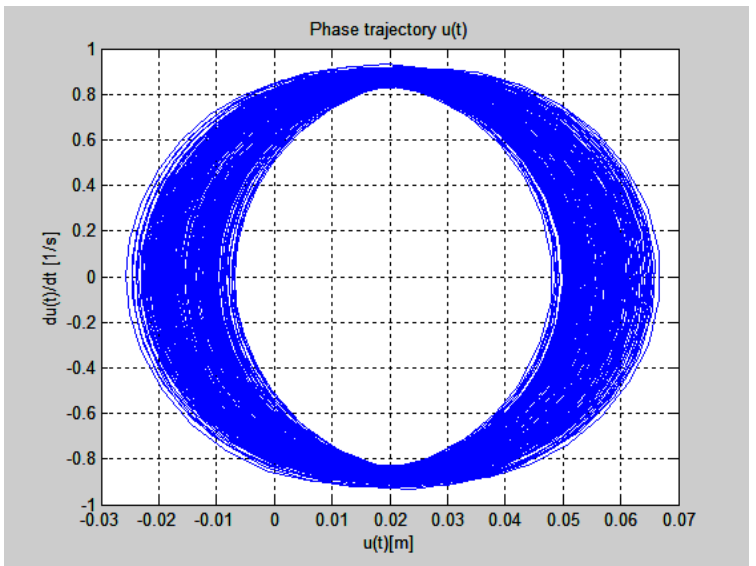

Figure 22: Phase trajectory of point $M$ : $\dot{u}=\dot{u}(u), \bar{m}=0.10 \mathrm{~kg} / \mathrm{m}, c=900 \mathrm{~N} / \mathrm{m}$

The phase characteristics for the two generalized coordinates are obtained. They conducted a study with variation of some parameters, such as distributed mass of the thread, coefficients of elasticity and integration time.

This study has a theoretical and methodological nature and contributes to the enrichment of knowledge in the field of nonlinear mechanics, as well as computational mathematics.

\section{ACKNOWLEDGEMENTS}

The author of this conference paper expresses his gratitude to Prof. Daniela Todorova, Rector of Todor Kableshkov University of Transport, Sofia, and ViceRectors, Prof. Petar Kolev and Prof. Krassimir Krastanov, for their support in the procedure for obtaining the scientific degree "Doctor of Science".

\section{REFERENCES}

[1] P. Palmieri, “A phenomenology of Galileo's experiments with pendulums," British Society for the History of Science, Vol. 42(4), pp. 479-513, doi: 10.1017/S0007087409990033, (2009) 
[2] C.D. Andriesse, "Huygens: The Man Behind the Principle," Cambridge University Press, ISBN 9780-521-85090-2, p. 134, (2005)

[3] W. Tobin , "The life and science of Léon Foucault: The man who proved the earth rotates," Cambridge University Press, ISBN 9780521808552, p. 272, (2003)

[4] P. Amore, A. Aranda, "Improved Linstedt-Poincare method for the solution of nonlinear problems," Jour. Sound Vib, Vol. 283(3-5), pp. 1115-1136, (2005)

[5] F.M.S. Lima, "Simple but accurate periodic solutions for the nonlinear pendulum equation," Revista Brasiliera de Ensino de Fisica, Vol. 41(1), pp. 1-6, doi: http://dx,doi.org/10.1590/1806-9126RBEF-2018-0202, (2019)

[6] H. Mazaheri, A. Hosseinzadeh, M.T. Ahmadian, "Nonlinear oscillation analysis of a pendulum wrapping on a cylinder," Scientia Iranica, Vol. 19(2), pp. 335-340, doi: 10.1016/j.scient.2012.02.014, (2012)

[7] V. Marinca, N. Herisanu, "Optimal auxiliary functions method for a pendulum wrapping on two cylinders," Mathematics, Vol. 8(1364), doi:10.3390/math8081364, pp. 2-18, (2020)

[8] K. Dean, "Conical Pendulum: Part 2. A detailed theoretical and computational analysis of the period, tension and centripetal forces," European J Physics Education, Vol. 8(1), pp. 11-30, (2017)

[9] P. Djou, V. Bozduganva, V. Vitliemov, "Dynamics of a pendulum with variable length and dry friction," Jour. Mechanics of machines, TU-Varna, Year XVII, Book 3, ISSN 0861-9727, pp. 41-44, (2009)

[10] V. Bozduganva, V. Vitliemov, "Dynamics of pendulum with variable length and dry friction as a simulator of a swing," Jour. Mechanics of machines, TU-Varna, Year XVII, Book 3, ISSN 0861-9727, pp. 45-48, (2009)

[11] D.N. Nikolov, M.B. Marinov, B.T. Ganev, T.S. Djamijkov, "Nonintrusive Measurement of Elevator Velocity Based on Inertial and Barometric Sensors in Autonomous Node," Proceedings of the International Spring Seminar on Electronics Technology, 10.1109/ISSE49702.2020.9121077, (2020)

[12] M. Marinov, D. Nikolov, B. Ganev, G. Nikolov, "Environmental noise monitoring and mapping," Proceedings of the International Spring Seminar on Electronics Technology, doi: 10.1109/ISSE.2017.8000992, (2017)

[13] B. Ganev, D. Nikolov, M.B. Marinov, "Performance evaluation of MEMS pressure sensors," Proceedings of 11 th National Conference with International Participation, ELECTRONICA 2020 , doi: 10.1109/ELECTRONICA50406.2020.9305140, (2020)
[14] Iliev IT, Ganev BT, Kanev IK. Study of the audio characteristics of mobile phones in the context of transmission of biomedical signals converted into sound. 11th National Conference with International Participation, ELECTRONICA 2020; doi: 10.1109/ELECTRONICA50406.2020.9305147, (2020)

[15] V. Vitliemov, I. Ivanov, "Robust-trajectory optimal synthesis of spread macro-particles," Jour. Mechanics of machines, TU-Varna, Year XXII, Book 2, ISSN 0861-9727, pp. 3-7, (2014)

[16] S. Hensel, M.B. Marinov, C. Kehret, M. StefanovaPavlova, "Experimental Set-up for Evaluation of Algorithms for Simultaneous Localization and Mapping," Communications in Computer and Information Science, Springer, Cham, Vol. 1251, https://doi.org/10.1007/978-3-030-56441-4_32, (2020)

[17] S. Hensel, M.B. Marinov, M. Schmitt, "System Setup for Synchronized Visual-Inertial Localization and Mapping", XXIX International Scientific Conference Electronics (ET), Sozopol, (Bulgaria), pp. 1-4, (2020)

[18] Sergeev Y.S., Sergeev S.V., D’yakonov A.A., Kononistov A.V., Karpov G.E., Mikryukov A.A., Automated Monitoring System for SelfSynchronizing Vibrational Drives. Russian Eng. Research, 38(2), pp. 86-90, doi:10.3103/S1068798X18020168, (2018).

[19] Sergeev S.V., Sergeev Y.S., Kononistov A.V., SelfSynchronized Controlled Vibration Drive with Automated Oscillation Parameters Monitoring System for High-Tech Equipment. Proceeding of the $40^{\text {th }}$ Int. Conf. on Industrial Engineering, Lecture Notes in Mechanical Engineering, Springer Nature Switzerland AG 2019, pp. 367-374, https://doi.org/10.1007/978-3-319-95630-5_40, (2019)

[20] Marinov MB, Ganev B, Djermanova N, Tashev TD. Analysis of sensors noise performance using allan deviation. In: 2019 28th International Scientific Conference Electronics, ET 2019, doi: 10.1109/ET.2019.8878552, (2019)

\section{Nelinearne oscilacije klatnanamotanog oko cilindra}

\footnotetext{
Anastas Ivanov Ivanov ${ }^{1 *}$

${ }^{1}$ Odsek za mehaniku, Univerzitet za saobraćaj Todor Kableškov, Sofija (Bugarska)

Proučavaju se velike oscilacije klatna. Klatno je materijalna tačka koja je okačena na elastični kabl sa nelinearnim karakteristikama. Masa kabla je prihvaćena. Umotan je oko savršeno krutog i fiksiranog cilindra. Sistem ima dva stepena slobode. Nelinearnost je posledica geometrijske $i$ fizičke prirode. Izveden je sistem dve diferencijalne nelinearne jednačine. Numeričko rešenje je izvedeno pomoću matematičkog paketa MatLab. Dobijaju se zakoni kretanja, generalizovane brzine $i$ ubrzanja $i$
} 
fazne putanje. Da bi se zadatak nastavio izradom stvarnog modela $i$ sprovođenjem eksperimentalnog istraživanja, određuju se projekcije brzine i ubrzanja materijalne tačke duž horizontalne $i$ vertikalne ose, kao $i$ njihove veličine. Dobijeni rezultati su grafički prikazani $i$ detaljno analizirani.
Ključne reči: Klatno, Geometrijska i fizička nelinearnost, Nelinearne oscilacije 